\title{
Utilization of Polyethylenimine (PEI) Modified Carbon Black Adsorbent Derived from Tire Waste for the Removal of Aspirin
}

\author{
Dyg Khairunnisa Awg Zaini, Norzita Ngadi, Muhd Asyiq Azman and Khairudin Ahmad \\ Faculty of Engineering, School of Chemical Engineering, Universiti Teknologi Malaysia, Johor Bahru, Johor 81310, Malaysia
}

\begin{abstract}
A new adsorbent was synthesized using polyethylenimine (PEI) on the carbon black to remove aspirin from an aqueous solution. In this study, adsorption performance of modified carbon black by polyethylenimine (PEI) on aspirin was investigated. Batch adsorption studies were performed to evaluate the effects of contact time, $\mathrm{pH}$ solution, temperature, and initial concentration on the adsorption of aspirin. For this study, the carbon black obtained from the pyrolysis of tire waste was used as a precursor for low-cost adsorbents. The carbon black was treated by $1 \mathrm{M}$ of hydrochloric acid solution to remove ash and sulphur content. Then, the treated carbon black was modified by impregnation with PEI in one to one weight ratio within 24 hours at $65{ }^{\circ} \mathrm{C}$ and then cross linked with $1 \%(\mathrm{w} / \mathrm{v})$ glutaraldehyde solution for one hour. The adsorption rate of aspirin by modified carbon black was rapid from 20 minutes to 60 minutes and reached equilibrium. Hence, the optimum contact time for this study is 60 minutes with $59.96 \%$ of aspirin removal and $29.98 \mathrm{mg} / \mathrm{g}$ adsorption capacity. The best performance for $\mathrm{pH}$ solution, temperature, and initial concentration was observed at pH $3(26.1 \mathrm{mg} / \mathrm{g}), 30{ }^{\circ} \mathrm{C}(26.9 \mathrm{mg} / \mathrm{g})$ and $20 \mathrm{ppm}(40.96 \mathrm{mg} / \mathrm{g})$ respectively.
\end{abstract}

Key words: Aspirin, adsorption, polyethylenimine, waste tire, modified adsorbent.

\section{Introduction}

Improper disposal of pharmaceutical waste might be hazardous and can contribute to the contamination of water supplies. Bbiomedical waste in Malaysia is expected to reach 33,000 tonnes per year by 2020 [1]. Many previous studies mentioned that traditional or conventional wastewater treatment methods are not sufficient as the pharmaceutical waste is not completely removed [2]. There are several advanced treatment methods that can be used to treat pharmaceutical waste such as autoclaving, ion-exchange, advanced oxidation process and biological treatment [3]. However, adsorption has become the most efficient method to treat pharmaceutical waste due to its cost effectiveness and simple design [4].

Disposal of tire waste becomes an issue because

Corresponding author: Norzita Ngadi, professor, research fields: wastewater treatment, protein fouling, catalytic reaction, surface coating and renewable fuel. they are immune to biological degradation. In this study, tire waste has become the precursor of low-cost adsorbent. The pyrolysis of tire waste produces carbon black which is suitable for the low-cost adsorbent due to higher carbon content. At the same time, the usage of solid product as an adsorbent can overcome the problem of tire waste management.

The usage of current commercialized activated carbon is limited due to its high operating cost that consumes energy during the activation step. Due to this problem, this study was conducted to explore new adsorbents which are cheaper and environmentally-friendly. Tire waste is highly abundant in Malaysia and can be one of the potential sources for low-cost adsorbent. Hence, this study will explore the modification of carbon black by polyethylinimine (PEI) as the adsorbent on the adsorption of the pharmaceutical compound without any activation step.

Polyethylenimine (PEI) is a cationic molecule that 
has a large number of amine groups and is well known as the modification agent on the adsorbent surfaces in order to increase the performance of the adsorption. In this study, PEI is chemically bonded to the carbon black surfaces through the crosslinking agent of glutaraldehyde.

There are two objectives of this research which are to modify carbon black by PEI and to study the effect of various parameters on the adsorption of aspirin. The raw carbon black was treated by $1 \mathrm{M}$ of hydrochloric acid and then modified by PEI using one to one weight ratio of carbon black to PEI. The adsorption studies were conducted on the effects of contact time, $\mathrm{pH}$ solution, temperature and initial concentration.

\section{Method and Materials}

Carbon black (CB) derived from tire waste was obtained from QCS Biotechnology Sdn Bhd at Senai, Johor. The tire waste underwent pryrolysis process in order to obtain the carbon black. Hydrochloric acid $(\mathrm{HCl})$ used in this study was purchased from Acros Organics. For the $\mathrm{pH}$ adjustment, $0.1 \mathrm{M}$ of $\mathrm{HCl}$ and sodium hydroxide $(\mathrm{NaOH})$ were used. PEI and glutaraldehyde were purchased from Acros Organics.

\subsection{Preparation of the Adsorbent}

The $\mathrm{CB}$ was impregnated in $1 \mathrm{M}$ of $\mathrm{HCl}$ solution (1 L) for 24 hours with $160 \mathrm{rpm}$ at room temperature. The treated carbon black was filtered and washed using distilled water until a neutral $\mathrm{pH}$ was obtained. Next, $5 \mathrm{~g}$ of treated CB was impregnated in $5 \%(\mathrm{w} / \mathrm{v})$ $\mathrm{PEI} /$ methanol solution (1:1 weight ratio of carbon black to PEI) within 24 hours in $65{ }^{\circ} \mathrm{C}$ at $160 \mathrm{rpm}$. Then, $100 \mathrm{~mL}$ of $1 \%$ (w/v) glutaraldehyde solution was added to the mixture for crosslinking reaction and agitated at $160 \mathrm{rpm}$, room temperature for 60 minutes. After that, the sample (PEI-CB) was filtered, washed and dried under $60{ }^{\circ} \mathrm{C}$ for 1 hour. The PEI-CB was then used for adsorption studies.

\subsection{Adsorption Studies}

The effect of contact time on adsorption of aspirin was performed by adding $0.1 \mathrm{~g}$ of PEI-CB into $50 \mathrm{~mL}$ of $100 \mathrm{ppm}$ of aspirin solution under $\mathrm{pH} 3,30{ }^{\circ} \mathrm{C}$, and $160 \mathrm{rpm}$. The sample was collected for UV-Visible analysis at every 10 minutes for the first 30 minutes and for every 30 minutes for the rest of the experiment until equilibrium was reached. The optimum contact time was used for the next three parameters with a different condition. For the $\mathrm{pH}$ influence, the $\mathrm{pH}$ of aspirin solution was varied from $\mathrm{pH} 3$ to $\mathrm{pH} 11$ and the best $\mathrm{pH}$ was used for the temperature influence $\left(30{ }^{\circ} \mathrm{C}, 50{ }^{\circ} \mathrm{C}\right.$ and $\left.70{ }^{\circ} \mathrm{C}\right)$. For the effect of initial concentration, the concentration of aspirin was varied from $10 \mathrm{ppm}$ to $100 \mathrm{ppm}$.

The amount of aspirin adsorbed at equilibrium time, $Q_{\mathrm{t}}$ was calculated using Eq. (1).

$$
Q_{\mathrm{t}}=\left(C_{\mathrm{o}}-C_{\mathrm{t}}\right) V / m
$$

Where $C_{\mathrm{o}}$ and $C_{\mathrm{t}}$ are the initial and concentrations at any time of aspirin solution ( $\mathrm{mg} / \mathrm{L})$, while $V$ is the total volume of the aspirin solution (L), and $m$ is the mass of adsorbent used $(\mathrm{g})$.

\section{Results and Discussions}

The adsorption studies for aspirin removal by modified carbon black (PEI-CB) have been studied under different contact time, $\mathrm{pH}$, temperature and initial concentration of aspirin.

\subsection{Time-Dependent Adsorption Studies}

The effect of contact time was studied to investigate the equilibrium time for the removal of aspirin by PEI-CB. Based on Fig. 1, the adsorption of aspirin increased with increased contact time and achieved equilibrium contact time after 60 minutes with almost $30 \mathrm{mg} / \mathrm{g}$ adsorption capacity.

At initial stages, it is a large number of vacant sites on the surfaces of PEI-CB which lead to rapid and high adsorption rate. The adsorption has reached 


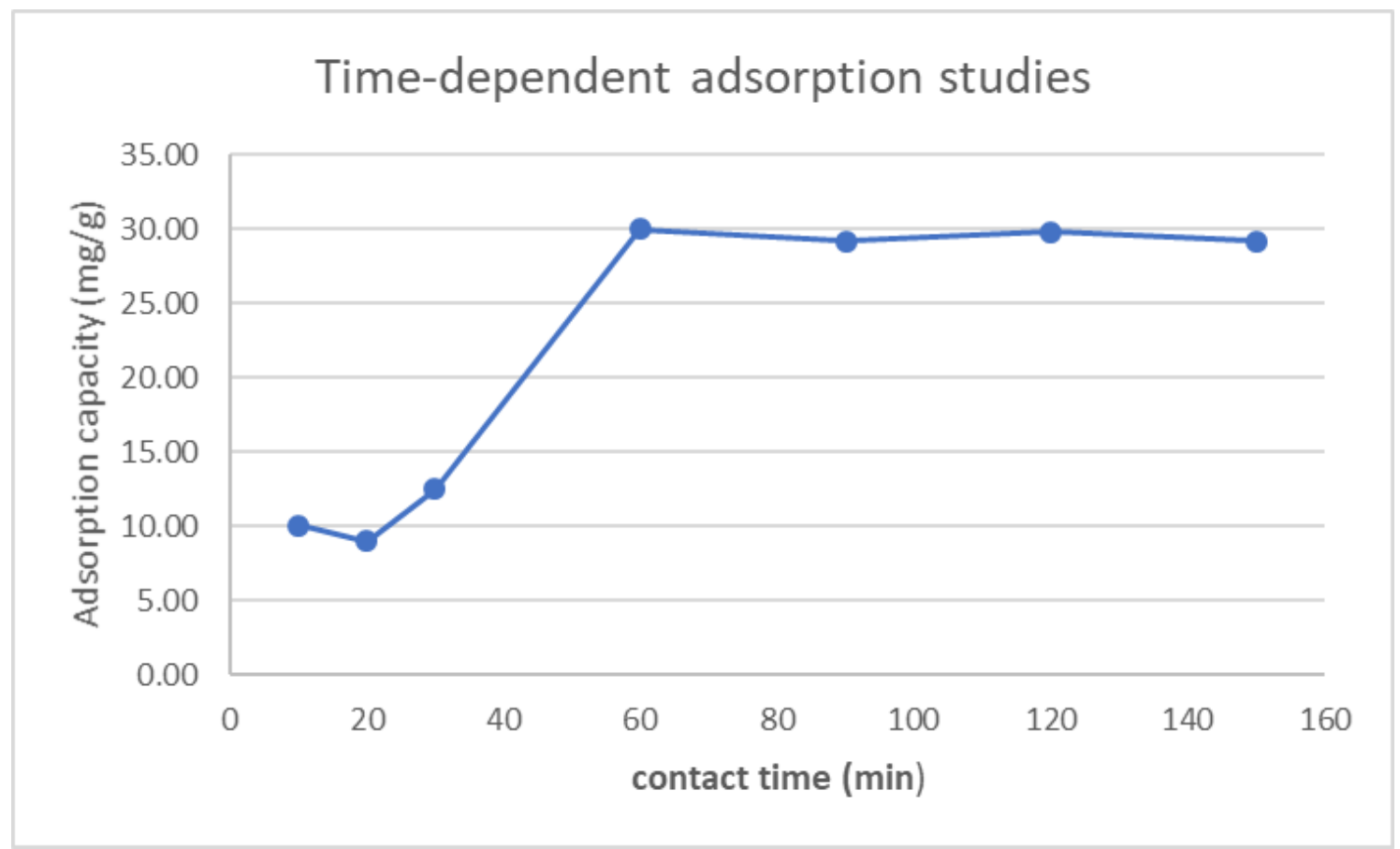

Fig. 1 Time-dependent of aspirin adsorption by PEI-CB.

equilibrium due to the occupied vacant sites with aspirin molecule. The same trend was shown in the previous study using rice hull activated carbon for the removal of aspirin [5]. Hence, for this study, the steady state for adsorption process is approximately at 60 minutes.

\subsection{Effect of pH on Adsorption Studies}

The effect of $\mathrm{pH}$ solution on the adsorption of aspirin was studied by varying the $\mathrm{pH}$ values $(3,5,7$, 9 and 11). The adsorption capacity of aspirin was significantly reduced from $\mathrm{pH} 3$ to $\mathrm{pH} 7$ and there was no adsorption occurring at higher $\mathrm{pH}(\mathrm{pH} 9$ and $\mathrm{pH}$ 11). This might be due to the competition of $\mathrm{OH}^{-}$ molecules and aspirin solution to attach on the cationic adsorbent surfaces. The highest adsorption capacity for aspirin was at $\mathrm{pH} 3$ with $24.81 \mathrm{mg} / \mathrm{g}$ as shown in Fig. 2. The adsorption of aspirin by $\mathrm{N}-\mathrm{CNT} / \mathrm{CD}$ and $\mathrm{Fe} / \mathrm{N}-\mathrm{CNT} / \mathrm{CD}$ from the previous study shows the same trend in which the highest adsorption occurred at low $\mathrm{pH}$ and unfavorable adsorption occurred at high $\mathrm{pH}[6]$.

\subsection{Effect of Temperature on Adsorption Studies}

Fig. 3 shows the performance of aspirin removal with three different temperatures. The performance indicates unfavorable reaction when the temperature increases. This phenomenon contributes to exothermic process [7]. In this study, the efficient temperature for adsorption of aspirin is below $30{ }^{\circ} \mathrm{C}$ with $24 \mathrm{mg} / \mathrm{g}$. The assumption has been made when the temperature rises, the interaction between adsorbate and the adsorbent becomes weaker which means physisorption process. This behavior has also been reported in a previous study [8].

\subsection{Effect of Initial Concentration on Adsorption Studies}

Fig. 4 shows the effect of initial concentration on the adsorption of aspirin by PEI-CB. The graph shows that the removal of aspirin decreased with increased concentration from $20 \mathrm{mg} / \mathrm{L}$ to $80 \mathrm{mg} / \mathrm{L}$. At higher concentration of aspirin, the number of solute molecule was higher than the number of sites available 


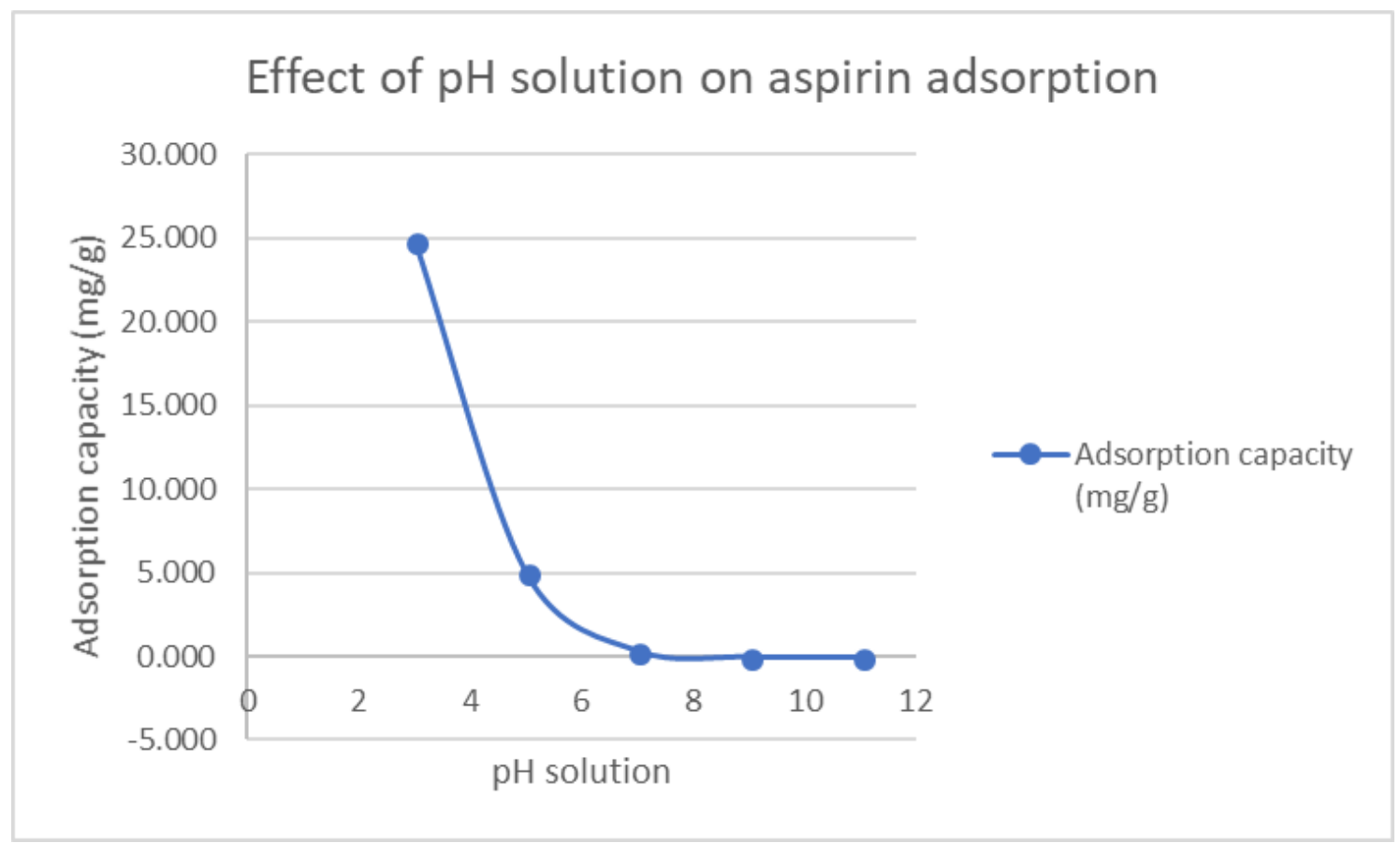

Fig. 2 Effect of pH solution on aspirin adsorption by PEI-CB.

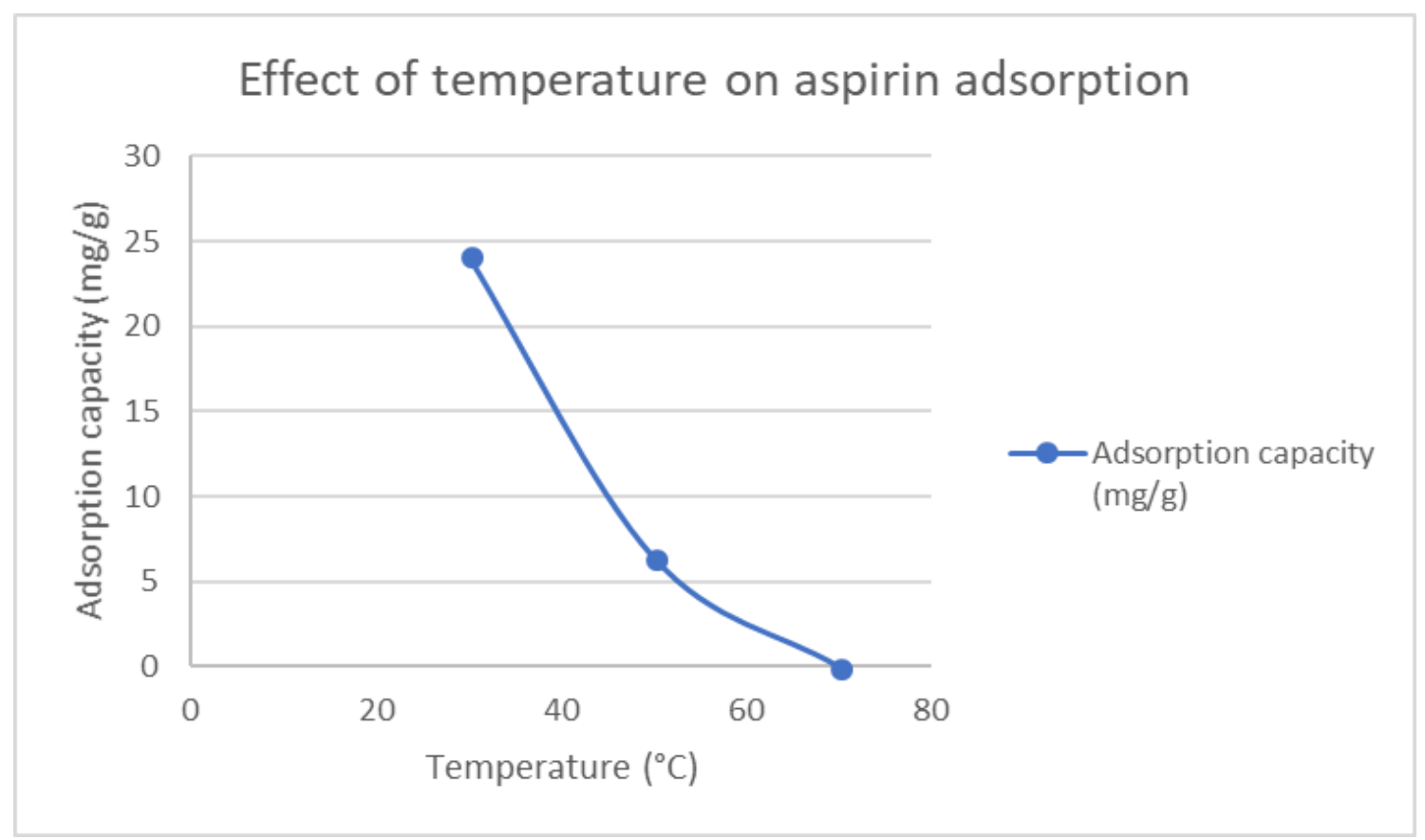

Fig. 3 Effect of temperature on aspirin adsorption by PEI-CB. 


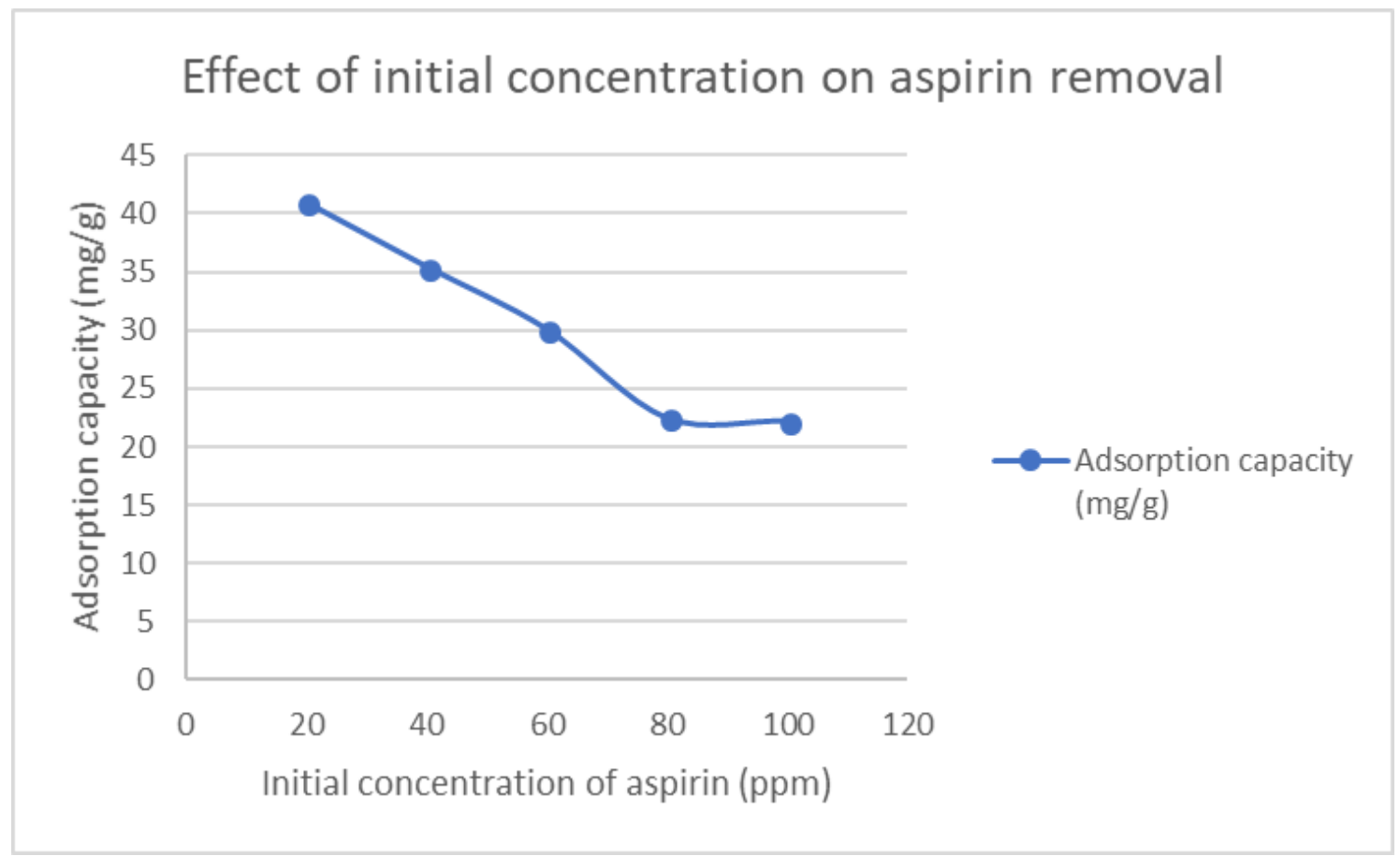

Fig. 4 Effect of initial concentration on aspirin adsorption by PEI-CB.

on the adsorbent surfaces. Therefore, lower removal of aspirin at a higher concentration as shown in Fig. 4 was due to the saturation limit achieved on the surfaces of the adsorbent.

\section{Conclusions}

The removal of aspirin as one of the pharmaceutical compounds from wastewater has been investigated. The effect of different parameters such as contact time, $\mathrm{pH}$ solution, temperature, and initial concentration of aspirin on the adsorption process has been studied. From the results obtained in this study, the following conclusions may be revealed:

(1) The PEI-CB used in this study has a potential to remove aspirin within 60 minutes with almost 30 $\mathrm{mg} / \mathrm{g}$ of adsorption capacity.

(2) $\mathrm{pH}$ solution can also influence the adsorption process whereby higher $\mathrm{pH}$ leads to lower performance of aspirin removal. The best $\mathrm{pH}$ for adsorption of aspirin is in the acidic region $(\mathrm{pH} 3)$.

(3) The temperature of the solution can also affect the adsorption of aspirin whereby the adsorption capacity of aspirin decreases when temperature increases. The best condition for adsorption process is at $30^{\circ} \mathrm{C}$.

(4) The performance of adsorption process decreases with the increase in of initial concentration.

(5) A study on the existence of pharmaceutical waste in the environment is crucial for the understanding of the risk of their presence to the environment and wastewater.

\section{Acknowledgments}

The authors would like to express their appreciation for the support of the sponsors with Project No. Q. J130000.2546.17H65 and Q. J130000.2646.14J29.

\section{References}

[1] Ambali, A. R., Bakar, A. N., and Merican, F. M. 2013. "Environmental Policy in Malaysia: Biomedical Waste, Strategies and Issues." Journal of Aministrative Science 10 (1): 1-17.

[2] Patneedi, C. B., and Prasadu, D. 2015. "Impact of Pharmaceutical Waste on Human Life and Environment." Rasayan Journal 8: 67-70.

[3] Pal, P., and Thakura, R. 2017. "Pharmaceutical Waste Treatment and Disposal of Concentrated Rejects: A Review." International Journal of Engineering Technology Science and Research 4: 2394-3386. 


\section{Tire Waste for the Removal of Aspirin}

[4] Rodrigues, L. A., da Saliva, M. L. C. P., Alvarez-Mendes, Coutinho, A. D. R., and Thim, G. P. 2011. "Phenol Removal from Aqueous Solution by Activated Carbon Produced from Avocado Kernel Seeds." Chemical Engineering Journal 174: 49-57.

[5] Mukoko, T., Mupa, M., Guyo, U., and Dziike, F. 2015. "Preparation of Rice Hull Activated Carbon for the Removal of Selected Pharmaceutical Waste Compounds in Hospital Effluent." Journal of Environmental and Analytical Toxicology 57.

[6] Mphahlele, K., Onyango, M. S., and Mhlanga, S. D. 2015. "Adsorption of Aspirin and Paracetamol from Aqueous
Solution Using Fe/N-CNT/ $\beta$-cyclodextrin Nanocomopsites Synthesized via a Benign Microwave Assisted Method." Journal of Environmental Chemical Engineering 3: 2619-30.

[7] Huang, J., Jin, X., Mao, J., Yuan, B., Deng, R., and Deng, S. 2012. "Synthesis, Characterization and Adsorption Properties of Diethylenetriamine-Modified Hypercrosslinked Resins for Efficient Removal of Salicylic Acid from Aqueous Solution." Journal of Hazardous Materials 217-218: 406-15.

[8] Marsh, H., and Reinoso, F.R. 2006, Activated Carbon: Elsevier Science. 